Relato de Caso

\title{
Identificação humana com a utilização de prótese total superior e de técnica de sobreposição de imagens
}

\section{Human Identification through the superimposition of images in total superior prosthesis}

\author{
Luiz Airton Saavedra de Paiva ${ }^{1}$, Ana Paula Alvarenga Antonio Rabelo ${ }^{2}$
}

Paiva LAS, Rabelo APAA. Identificação humana com a utilização de prótese total superior e de técnica de sobreposição de imagens. Saúde, Ética \& Justiça. 2010;15(1):40-5.

Resumo: A determinação da identidade individual representa o objetivo principal na perícia antropológico-forense em despojos humanos. Para tanto, utilizam-se técnicas fundamentadas na comparação entre dados de registro antemortem com os obtidos pelo exame realizado no cadáver. A técnica de sobreposição de imagens, frequentemente utilizada no segmento crânio-facial, foi aplicada no caso apresentado como prova da adaptabilidade anatômica entre uma prótese dentária utilizada em vida e o rebordo alveolar e o palato do crânio periciado.

DESCRITORES: Cronotanatognose; Entomologia forense; Criminalistica.

INTRODUÇÃO

A preocupação em se identificarem indivíduos pode ser observada na história da humanidade desde os seus primórdios, nos primeiros registros da vida do homem integrado em uma sociedade.

A partir desse fato, inúmeros métodos e possibilidades foram utilizados a fim de criar condições para realizar a atribuição de uma identidade e seu reconhecimento futuro.

Segundo Amoedo ${ }^{1}$, a identificação possui um caráter humanitário e social importantíssimo, como também imprescindível para que as decorrentes providências jurídicas relativas ao óbito possam ser tomadas.

Através do tempo, muitos autores buscaram definir o conceito de identidade. Simas Alves ${ }^{2}$ definiu como sendo "um conjunto de caracteres físicos, funcionais e psíquicos normais ou patológicos, que individualizam determinada pessoa".

Arbenz ${ }^{3}$ afirma que "identificação corresponde aos diversos processos, métodos e sistemas para reconhecer uma pessoa viva ou morta, ou ainda, os restos cadavéricos, bem como aos atos mediante os quais se pode determinar e estabelecer a identidade de alguém".

\footnotetext{
Mestre e Doutor em Ciências pela Faculdade de Medicina - USP.

2 Especialista em Odontologia Legal pela Faculdade de Odontologia - USP.

Endereço PARA CoRRESPONDÊNCIA: Rua Capitão Manuel Rudge, 707. Vila Oliveira. Mogi das Cruzes. SP. CEP 08780-290.

E-mail: luizairtonsaavedra@ @erra.com.br
} 
Com grande freqüência, os Institutos de Medicina Legal recebem corpos que chegam esqueletizados, espostejados ou em avançado estado de putrefação, impossibilitando a aplicação dos métodos convencionais de identificação (reconhecimento visual, datiloscopia).

Em tais situações, as técnicas utilizadas pela antropologia forense para estimar idade, sexo, ancestralidade, estatura entre outras características, são de grande importância para proceder à identificação de alguém.

$\mathrm{Na}$ vida em sociedade, todo o indivíduo, em algum momento e de alguma forma, foi identificado. Ao nascer, quando a impressão plantar é registrada no prontuário médico, já se torna uma pessoa individualizável. São estes registros obtidos ao longo da vida do individuo, que podem auxiliar o perito na confirmação de uma identidade individual, visto que a perícia de identificação sempre busca utilizar técnicas fundamentadas na comparação entre os dados registrados ante-mortem com os obtidos no exame realizado no cadáver ${ }^{4}$.

Paiva ${ }^{5}$ relata que a determinação da identidade individual dos restos cadavéricos estudados representa o objetivo maior de toda a perícia de identificação médico-legal.

Algumas possibilidades técnicas podem ser viabilizadas a partir de registros anteriores do caso, como o estudo comparativo da arcada dentária do cadáver com fichas odontológicas descrevendo tratamentos anteriormente realizados. Características individuais, como presença de próteses, podem também favorecer a identificação, principalmente nos casos em que o cadáver não possui dentes (edentados total). Outra possibilidade é a comparação entre radiografias realizadas antemortem, com radiografias post-mortem.

A sobreposição de imagens pode representar também um meio auxiliar da identificação e se tornar, em alguns casos, determinante para o direcionamento da perícia forense ${ }^{6}$.

\section{Apresentação do caso}

Foi recebido para exame necroscópico no Instituto Médico-Legal da cidade de Guarulhos um esqueleto incompleto, composto por um conjunto de ossos secos e inodoros. Feito o registro fotográfico, os despojos foram encaminhados para o devido preparo.

Após a devida limpeza, o conjunto ósseo foi classificado e remontado em mesa para estudo.

Considerados no seu conjunto, os aspectos antroposcópicos e antropométricos do esqueleto, objeto do estudo, concluiu-se tratar de:

1. Esqueleto pertencente à espécie humana;

2. Do sexo feminino;

3. Com características de cor de pele predominantes do grupo leucoderma;

4. Com idade estimada de mais de 60 anos;

5. Com estatura de cerca de 1,60 m;

6. Causa da morte não determinada pelo estudo;

7. A morte teria ocorrido em um período de ao menos 90 dias antes de seu recebimento em nosso serviço;

8. Apresenta como sinal particular ser edentado.

Em 13 de outubro de 2009 foi entregue no Serviço de Antropologia Forense uma prótese dentária de arco superior desgastada (Figura 1), encaminhada por familiares da Sra. L. C. S., 71 anos de idade, desaparecida desde o ano de 2008, para fins de confrontação com o esqueleto objeto do presente estudo. A referida prótese encontrava-se sob guarda da família por encontrar-se em desuso (sic).

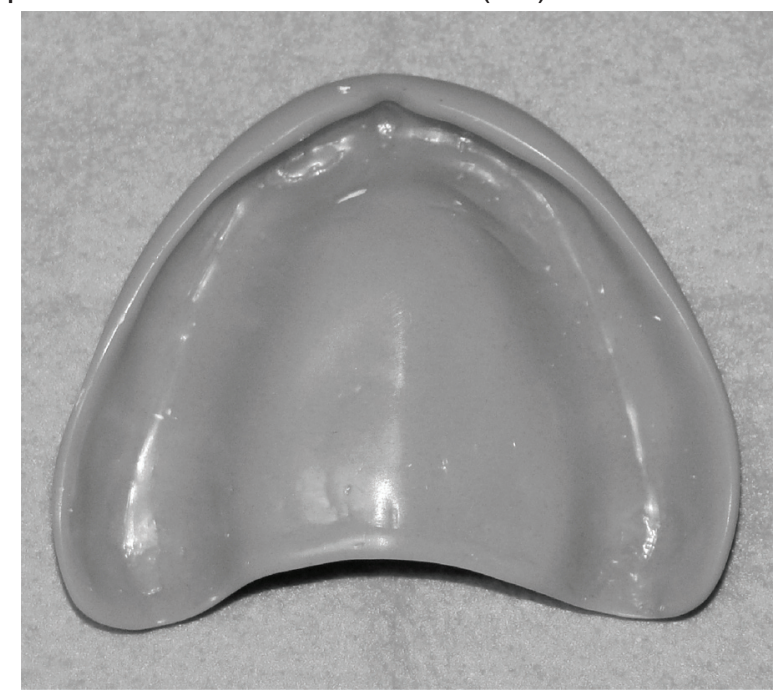

Figura 1 - Prótese dentária encaminhada ao IML de Guarulhos 
Paiva LAS, Rabelo APAA. Identificação humana com a utilização de prótese total superior

\section{DESCRIÇÃO DAS TÉCNICAS EMPREGADAS}

Um modelo da superfície interna da prótese foi obtido em gesso pedra tipo 3 por meio de moldagens subseqüentes com silicona por condensação (tipo pesada) e hidrocolóide tipo irreversível (Figura 3). Este modelo, referente à superfície anatômica da área chapeável da maxila do portador da prótese, foi utilizado para a comparação anatômica com a área correspondente no crânio recebido para exame.

Os seguintes procedimentos de comparação anatômica entre a prótese recebida e o crânio estudado foram realizados:

1. Prova de adaptação da prótese ao crânio (Figura 2);

2. Comparação do alinhamento entre o rebordo alveolar da maxila do crânio em análise e do modelo obtido em gesso (Figura 4);

3. Comparação entre as alterações anatômicas de relevo do rebordo alveolar superior e do palato do crânio em análise com a superfície de adaptação do modelo em gesso, por meio da técnica de sobreposição de imagens (Figura 5).

DıSCUSSÃO

$\mathrm{Na}$ literatura podemos encontrar diversos relatos de casos em que características individuais, como próteses dentárias, fraturas consolidadas, elementos dentários, entre outras, foram determinantes no processo de identificação de uma pessoa.

Tanto na atribuição de uma identidade, como em sua exclusão, observamos a importância da obtenção de registros ante-mortem e postmortem que possam de alguma forma ser confrontados no exame pericial.

Daruge $\mathrm{Jr}^{7}$ cita, em seu estudo, o caso de Luiz Carlos, filho de Luiz XVI, em que se conseguiu excluir a identidade de seus presumíveis restos cadavéricos pelo estudo do esqueleto encefálico e dos demais elementos sinaléticos dos dentes.

O autor ressalta também a identificação de George Parkman, assassinado em Boston, em 1850. Nesse caso, o assassino, após esquartejar o corpo, queimou a cabeça na fornalha de seu laboratório. Porém, nas cinzas foram encontrados dentes de porcelana e restaurações em ouro pertencentes à Parkman e que foram reconhecidas pelo Cirurgião-Dentista que as havia realizado.

Em odontologia, a moldagem constitui uma técnica que visa a copiar e reproduzir as arcadas alveolares e estruturas afins, para a obtenção de um modelo que será a cópia fiel das mesmas, e que poderá servir de base para confecção de aparelhos protéticos.

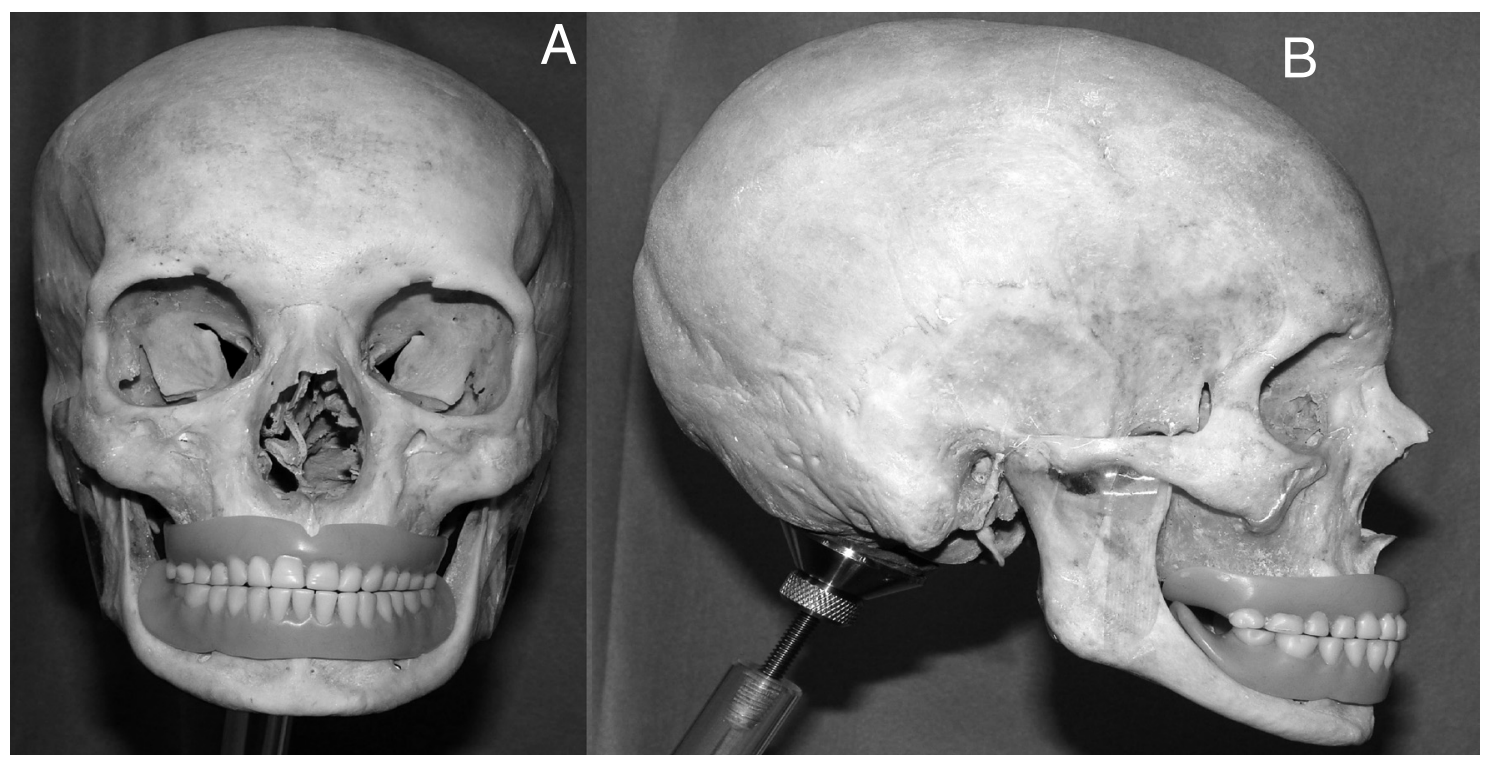

Figura 2 - Prova de adaptação da prótese ao crânio em estudo: a) em vista frontal; b) em vista lateral. 


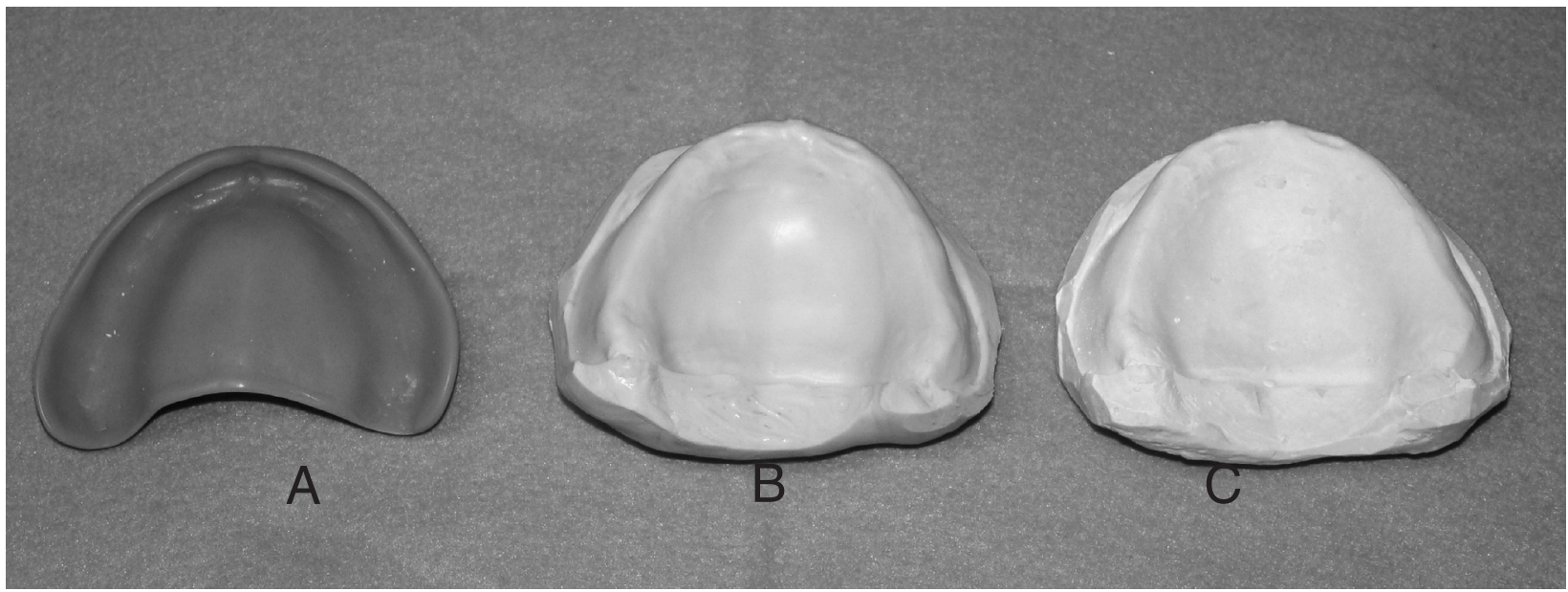

Figura 3 - a) prótese; b) molde em silicona; c) molde em gesso

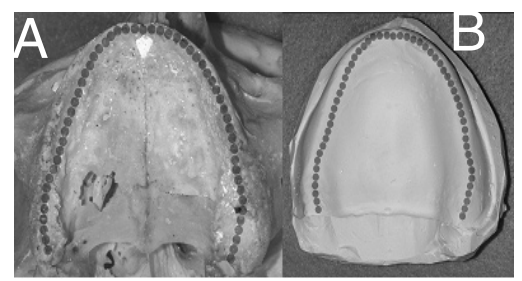

Figura 4 - a) maxila; b) molde em gesso

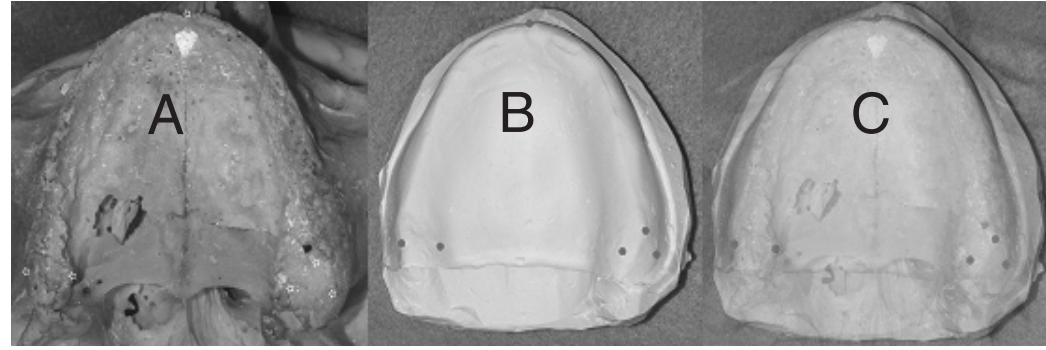

Figura 5 - a) rebordo alveolar; b) modelo em gesso; c) imagens sobrepostas

No caso de um edentado total, os rebordos alveolares, recobertos ou não por tecido gengival, representam a base de sustentação da prótese, sendo o rebordo ósseo a base de sustentação profunda.

Segundo Netto ${ }^{8}$, a base da prótese total deve recobrir tanta superfície de suporte quanto possível e reproduzir fielmente os acidentes anatômicos da boca em seu estado atual. Modelos em gesso e moldes obtidos por meio de moldagem do individuo em vida também podem ser fonte de grande informação para auxílio da perícia.

Com o aprimoramento dos métodos auxiliares no processo de identificação humana e os avanços tecnológicos obtidos nesta área, a utilização da técnica de sobreposição de imagens 
Paiva LAS, Rabelo APAA. Identificação humana com a utilização de prótese total superior

mostra-se de grande importância como auxiliar na identificação humana, mesmo em casos em que seus achados sejam classificados como apenas consistentes e não categóricos ${ }^{6}$.

No caso aqui relatado, a consistência da identificação se fundamentou nos seguintes aspectos:

1. A total compatibilidade entre os dados de conclusão do Exame Antropológico Forense relacionados ao sexo, à idade, à estatura, à cor da pele e à época da morte do caso estudado e os dados do histórico da pessoa objeto de estudo comparativo;

2. A perfeita adaptabilidade da prótese recebida ao crânio estudado;

3. A completa coincidência anatômica entre o modelo obtido da prótese e o rebordo alveolar e palato do crânio em estudo.

\section{Conclusão}

O desenvolvimento da técnica de identificação médico-legal descrita no presente trabalho, permitiu as seguintes conclusões:

1. A importância do caráter de individualidade das próteses dentárias, dos mais variados tipos, como elemento de relevante importância na identificação humana;

2. A importância da completa pesquisa em locais de encontro de cadáver objetivando o recolhimento do maior número de elementos do complexo maxilo-mandibular que possam contribuir para o melhor resultado do trabalho pericial;

3. A importância de um cuidadoso estudo de adaptabilidade entre uma prótese dentária de usuário identificado, e o crânio em estudo que permitiu por meio da técnica descrita e da aplicação de critérios científicos, atribuir identidade ao indivíduo;

4. A técnica de sobreposição de imagens, frequentemente utilizada entre os elementos do segmento crânio-facial, pode também ser empregada em outros segmentos anatômicos.

Paiva LAS, Rabelo APAA. Human identification through the superimposition of images in total superior prosthesis. Saúde, Ética \& Justiça. 2010;15(1):40-5.

ABSTRACT: Determining the individual identity in human remains is the main objective of forensic anthropology expertise. For this purpose, there are techniques based on comparison of ante-mortem register data and records obtained through the examination of the corpse. The technique of superimposing images, often used in craniofacial segment, is presented in this case study as an evidence of anatomical adaptability between a dental prosthesis used in life and the alveolar ridge and the palate skull of the studied object.

KEY WORDS: Human identification; Forensic science; Total prosthesis; Forensic dentistry.

REFERÊNCIAS

1. Amoedo O. Study of the teeth after death from a 2. Simas Alves E. Medicina legal e deontologia. medical stand point. Dental Digest. 1903; 9:604-8. Curitiba; 1965. 
Paiva LAS, Rabelo APAA. Identificação humana com a utilização de prótese total superior

3. Arbenz OG. Medicina legal e antropologia forense. Rio de Janeiro: Atheneu; 1988.

4. Garrido GR. Evolução dos processos de identificação humana: das características antropométricas ao DNA [citado 28 jul. 2010]. Disponível em: http//:www.geneticanaescola.com. br/ano4vol2/ms10_008.pdf

5. Paiva LAS. Identificação médico-legal. Rev Univ Grarulhos-Série Ciên Hum Sociais. 1997;2(2):41-50.

6. Paiva LAS de, Melani RFH, Oliveira SVT. Identificação humana através da sobreposição de imagens. Saúde Ética \& Justiça. 2005;10(1/2):1-5.

7. Daruge Jr E. Identificação humana pelos eventos odontológicos e alterações dentárias através de um método computadorizado [Dissertação]. Piracicaba: Faculdade de Odontologia de Piracicaba da Unicamp; 1993.

8. Netto $\mathrm{CH}$. Prótese total mucosuportada resumo de aulas teóricas e comentários. Rev XXV Janeiro, FOUSP. 1971;30:29-44.

Recebido em: 17/03/2010

Aprovado em: 26/03/2010 